\title{
Blue Cones and Cone Bipolar Cells Share Transcriptional Specificity as Determined by Expression of Human Blue Visual Pigment-derived Transgenes
}

\author{
M. Isabel Chiu1,a and Jeremy Nathans ${ }^{1,2,3}$ \\ Departments of ${ }^{1}$ Molecular Biology and Genetics, ${ }^{2}$ Neuroscience, and ${ }^{3}$ Ophthalmology, Howard Hughes Medical Institute, \\ Johns Hopkins University School of Medicine, Baltimore, Maryland 21205
}

\begin{abstract}
Sequences $5^{\prime}$ of the human blue visual pigment gene have been assayed in transgenic mice for their ability to direct cell-type-specific expression of linked $\beta$-galactosidase (lacZ) and placental alkaline phosphatase ( $P$ ALP1) reporters. Constructs containing either 5.4 kilobases $(\mathrm{kb})$ or $0.47 \mathrm{~kb}$ of 5 flanking DNA direct expression exclusively to the retina. Within the retina, transgene expression is confined to blue cones and cone bipolar cells, as determined, respectively, by double labeling with anti-cone pigment antibodies and by morphologic analyses. These results imply that blue cones and cone bipolar cells have partially overlapping transcriptional specificities.
\end{abstract}

[Key words: blue cone visual plgment promoter, cone bipolar cells, retina-specific expression, alkaline phosphatase transgenes]

The retina is an attractive part of the CNS in which to study the determination of cell identity. The vertebrate retina consists of a small number of morphologically and functionally distinct cell types arranged in three layers. Photoreceptor cell bodies reside in the outer nuclear layer; horizontal, bipolar, and amacrine cell bodies reside in the inner nuclear layer; and ganglion cell bodies reside in the ganglion cell layer. Photoreceptors synapse onto hipolar cells in the outer plexiform layer, which in turn synapse onto ganglion cells in the inner plexiform layer, a relay system that forms the principal path of information flow. Horizontal and amacrine cells modify spatial and temporal responses by contacting photoreceptor and bipolar cells in the outer plexiform layer, and bipolar and ganglion cells in the inner plexiform layer, respectively (Rodieck, 1973; Dowling, 1987).

All vertebrate retinas have two anatomically and functionally distinct classes of photoreceptors, rods and cones. Rods contain

\footnotetext{
Received Sept. 28, 1993; accepted Nov. 24, 1993.

We thank Ms. L. Zhou for assistance with animal care; Ms. B. Klaunberg, Ms. E. Cooke, Dr. W. Reid, and Dr. J. Gearhart for injection and implantation of mouse eggs; Dr. Y. Wang and Dr. D. Zack for the mouse genomic clone gM2; Dr. J. Peschon for the gift of plasmid placF; Mr. S. Fields-Berry and Dr. C. Cepko for the gift of the PALP1 cDNA; Dr. C. Rilcy, Ms. A. Collector, Ms. C. Davenport, Ms. J. Ptak, and Ms. C. Wendling for synthetic oligonucleotides; Drs. Y.-W. Peng, E. Raviola, R. Reed, and C. Riley for helpful discussions; Dr. S. Merbs for anticone pigment antisera; and Drs. C.-H. Sung, Y. Wang, M. Xiang, Mr. H. Zhou and $\mathrm{Mr}$. H. Sun for helpful comments on the manuscript. This work was supported by the Howard Hughes Medical Institute and the National Retinitis Pigmentosa Foundation.

Correspondence should be addressed to Dr. Jeremy Nathans, 805 PCTB, 725 North Wolfe Street, Johns Hopkins University School of Medicine, Baltimore, MD 21205.

a Present address: Mitofix, Inc., One Kendall Square, Building 600, Cambridge, MA 02139.

Copyright (C) 1994 Society for Neuroscience $0270-6474 / 94 / 143426-11 \$ 05.00 / 0$
}

the light-sensitive visual pigment rhodopsin, and mediate vision in dim light. Cones mediate vision at higher light levels and, depending upon the species, comprise two or more classes, each containing a visual pigment with a distinctive absorption spectrum. Sequence analysis of visual pigment genes has revealed an cvolutionary split between long- and short-wave-sensitive cones that predates the vertebrate radiation (Nathans et al., 1986; Takao et al., 1988; Kuwata et al., 1990; Tokunaga et al., 1990; Yokoyama and Yokoyama, 1990; Johnson et al., 1993). Among Old World primates, including humans, a more recent duplication of the long-wavelength pigment gene has permitted the evolution of red and green cones (Nathans et al., 1986; Neitz et al., 1991; Ibbotson et al., 1992).

A parallel series of evolutionary duplications is seen among bipolar cells. The most prominent distinction is between rod bipolar cells and cone bipolar cells. Present evidence indicates that there is only one type of rod bipolar cell in the mammalian retina. These cells receive inputs exclusively from rods and depolarize in response to light. By contrast, cone bipolar cells can be divided into a number of classes by several criteria. First, they fall into two classes with respect to the polarity of their response to light stimulation of the cones with which they have direct contact and which therefore comprise the center of their receptive fields. Bipolar cells that hyperpolarize in response to light generate an off-center, on-surround receptive field, whereas bipolar cells that depolarize in response to light generate an oncenter, off-surround receptive field. Second, cone bipolar cells can be subdivided by exclusively morphologic criteria such as the degree of dendritic spread, the ultrastructure of the synaptic contact with the cone pedicle, and the sublamina of the inner plexiform layer in which they synapse. Finally, cone bipolar cells differ with respect to the types and numbers of cones contacted, as seen most simply in the primate fovea, where each bipolar cell contacts only a single cone (reviewed in Rodieck, 1988; Wassle and Boycott, 1991). Mariani (1984) and Kouyama and Marshak (1992) have presented histologic evidence for a blue cone-specific subtype of bipolar cells in the peripheral retina of the macaque. Whether some bipolar cells receive synaptic inputs from more than one type of cone remains an open question.

What are the molecular events that give each of these cells its distinctive identity? Analysis of cell lineage in the developing mammalian and amphibian retina indicates that commitment to a particular cell fate occurs after the final mitosis, suggesting that retinal cell fate depends on local cucs that act late in development (Turner and Cepko, 1987; Holt et al., 1988; Turner et al., 1990). To approach this question at a genetic level, several 
groups have begun to dissect the cis-acting regulatory sequences involved in cell-type-specific gene expression in the retina. Sequences controlling expression of bovine and murine rhodopsin in rods (Lem et al., 1991; Zack et al., 1991), the human red and green cone pigment genes in cones (Wang et al., 1992), and the L7 gene in cercbcllar Purkinje cclls and retinal bipolar cells (Oberdick et al., 1990) have been partially defined using reporter constructs in transgenic mice. The experiments reported here were initially aimed at defining those sequences adjacent to the human blue pigment gene that direct its expression specifically to blue cones. Unexpectedly, we observed that the transgene constructs were expressed in both blue cones and a subset of cone bipolar cells.

\section{Materials and Methods}

\section{Cloning and sequencing of blue visual pigment homologs}

The isolation of the human blue visual pigment gene has been described (Nathans et al., 1986). The 5.4 kilobase $(\mathrm{kb})$ sequence 5 ' of the translation start site was determined on both strands using fragments from genomic clonc gJHN23 (Nathans et al., 1986). To isolate the bovine and murine blue pigment genes, a human blue visual pigment cDNA (hs37; Nathans et al., 1986) was used as a probe to screen Sau 3A partialdigest genomic libraries in lambda EMBL3 (Frischauf et al., 1983). From the bovine library, six overlapping clones were obtained that encompass the blue visual pigment gene as determined by sequencing the coding region. Fragments from clone gB1 8 containing sequences upstream of the gene were subcloned into plasmid vectors pUC118 and pUC119, and a $4.6 \mathrm{~kb}$ sequence immediately $5^{\prime}$ of the translation start site was determined on both strands. From the mouse genomic library, a clone, gM2, was shown to contain the mouse blue pigment gene as determined by sequencing the coding region (I. Chiu., D. Zack, Y. Wang, and J. Nathans, unpublished observations). From gM2, a $2.2 \mathrm{~kb}$ sequence immediately $5^{\prime}$ of the translation start site was determined on both strands using subclones in pUC118 and pUC119 as templates. The $5^{\prime}$ flanking sequences shown in Figure 6 have been submitted to the Genome Sequence Database with accession numbers L27829 (bovine), L27830 (human), and L27831 (mouse).

\section{Generation of transgenic mouse lines}

Three DNA fragments were used for generating transgenic animals. Two of these contain promoter fragments that extend either from the Sall site at -5466 base pairs $(\mathrm{bp})(\mathrm{hB}-5.4 \mathrm{lacZ})$ or from the PstI site at -470 bp (hB-0.47lacZ) to the translation start site of the human blue pigment gene, fused to the Escherichia coli $\beta$-galactosidase gene lac $Z$ (placF, Peschon et al., 1987). A third fragment contains the $5466 \mathrm{bp}$ fragment fused to the human placental alkaline phosphatase gene $P A L P I$ (hB$5.4 A P ; 1.9 \mathrm{~kb}$ BgllI fragment from pJAP, Fields-Barry et al., 1992). The translation start of the human blue pigment gene in these constructs has been modified to encode an NcoI site, and in the final fusions all have the scquence 5' ATGCAAGCTCCCATG $3^{\prime}$ in place of the ATG at the translation start site. Each transgene fragment also contains $0.5 \mathrm{~kb}$ of the 3 ' sequence from the mouse protamine gene $m P l$, which provides an intron and a polyadenylation site.

DNA fragments were purified by agarose gel electrophoresis, and microinjected into the pronuclei of $(\mathrm{C} 57 \mathrm{BL} / 6 \mathrm{~J}$ male $\times \mathrm{B} 6 \mathrm{AF} 1$ female $)$ embryos at $4 \mathrm{ng} / \mu \mathrm{l}$. Injected eggs were transplanted into CD1 mothers following procedures described in Hogan et al. (1986). Potential founder animals were tested for the presence of the transgene by PCR analysis of tail DNA. Those animals showing a positive reaction by PCR were outcrossed to $\mathrm{C} 57 \mathrm{BL} / 6 \mathrm{~J}$ animals to yield F1 offspring, hemizygous for the transgene locus. One of the transgenic founder mice gave rise to descendants with either a high expression profile, a medium expression profile, or both, each of which when outcrossed subsequently gave rise to progeny with only high or medium expression profilcs, respectively.

\section{Detection of transgene expression and immunocytochemistry}

Histochemical methods were adapted and modified from Zack et al. (1991), Wang et al. (1992), and Fields-Berry et al. (1992).

$\beta$-Galactosidase. Following enucleation, the sclera and choroid were peeled away from the retina starting at the optic disk, after which the cornea, iris, and lens were removed. The retina was fixed in $0.5 \%$ glu- taraldehyde in phosphate-buffered saline with $2 \mathrm{mM} \mathrm{MgCl}_{2}$ (PBS- $\mathrm{Mg}$, $\mathrm{pH} \mathrm{7.3)} \mathrm{for} 10 \mathrm{~min}$ at room temperature, washed in PBS-Mg, and incubated in $\mathrm{X}$-gal (5-bromo-4-chloro-3-indolyl- $\beta$-D-galactopyranoside) staining solution ( $1 \mathrm{mg} / \mathrm{ml} \mathrm{X}$-gal, $5 \mathrm{~mm} \mathrm{~K}_{3} \mathrm{Fe}(\mathrm{CN})_{6}, 5 \mathrm{~mm}$ $\mathrm{K}_{4} \mathrm{Fe}(\mathrm{CN})_{6} \cdot 3 \mathrm{H}_{2} \mathrm{O}$ in PBS-Mg) at $37^{\circ} \mathrm{C}$ for $12-18 \mathrm{hr}$. Following washes in PBS-Mg, the retina was viewed as a whole-mount or flat mount. For frozen sections, the retina was postfixed in $4 \%$ paraformaldehyde in PBS-Mg for $4-6 \mathrm{hr}$ at $4^{\circ} \mathrm{C}$, transferred to $30 \%$ sucrose in PBS- $\mathrm{Mg}$ for $12-18 \mathrm{hr}$ at $4^{\circ} \mathrm{C}$, and then quick frozen in a 2-methylbutane bath prechilled in liquid nitrogen and embedded in OCT medium (Miles, Elkhart, IN). Frozen sections $10 \mu \mathrm{m}$ thick were cut on a Microm cryostat at $-20^{\circ} \mathrm{C}$ and mounted on gelatin-coated microscope slides. The sections were air dried and stored at $-80^{\circ} \mathrm{C}$ until use. Upon thawing, the slides were washed in PBS-Mg, fixed for $3 \mathrm{~min}$ in $4 \%$ paraformaldehyde, washed in PBS-Mg, and mounted for viewing in either Aquamount (Polysciences, Warrington, PA) or in 50\% glycerol in PBS.

Antibody and $\beta$-galactosidase double labeling. For double labeling, affinity-purified rabbit antibodies directed against either the human blue visual pigment (JH455) or human red and green visual pigments (JH492) were prepared as described (Wang et al., 1992). Sections were prepared and postfixed as described above and then immersed in ice-cold methanol for $3 \mathrm{~min}$ to ensure permeabilization of cell membranes. After several washes in PBS-Mg, the slides are incubated with $5 \%$ normal goat serum for $1 \mathrm{hr}$, then reacted with affinity-purified rabbit antibodies (diluted 1:2000 relative to serum) directed against either the human blue visual pigment or human red and green visual pigments in PBS$\mathrm{Mg}$ with $1 \%$ normal goat serum for $12-18 \mathrm{hr}$ at $4^{\circ} \mathrm{C}$, and then incubated with biotinylated goat anti-rabbit IgG at 1:200 for $2 \mathrm{hr}$ (Vector, Burlingame, CA), and with avidin-biotin-peroxidase complex at 1:100 for $2 \mathrm{hr}$ (Vector). The slides were washed with four changes of PBS-Mg for a total of $2 \mathrm{hr}$ between incubations. Immunoperoxidase activity was visualized by incubation with diaminobenzidine $(0.5 \mathrm{mg} / \mathrm{ml})$ and hydrogen peroxide $\left(0.015 \%\right.$ ), followed by a $10 \mathrm{~min}$ wash in $\mathrm{H}_{2} \mathrm{O}$, and final mounting in PBS with $50 \%$ glycerol.

Alkaline phosphatase. Following enucleation, eyes were fixed in $4 \%$ paraformaldehyde at $4^{\circ} \mathrm{C}$ for $30 \mathrm{~min}$, after which the anterior segments were removed, and the eye cups fixed for an additional 12-18 hr. The fixed eye cups were then immersed in 30\% sucrose in PBS and frozen for sectioning as described above. The sections were postfixed in $4 \%$ paraformaldehyde for $5 \mathrm{~min}$, rinsed in PBS, and heated to $65^{\circ} \mathrm{C}$ for 45 min to preferentially reduce endogenous alkaline phosphatase activity. The sections were stained for transgenic alkaline phosphatase activity in AP buffer ( $100 \mathrm{~mm}$ Tris $\cdot \mathrm{HCl}$, pH $9.5,100 \mathrm{~mm} \mathrm{NaCl}, 50 \mathrm{~mm} \mathrm{MgCl}_{2}$ ) containing $0.1 \mathrm{mg} / \mathrm{ml} \mathrm{X}$-Phos (5-bromo-4-chloro-3-indolyl-phosphate) and $1 \mathrm{mg} / \mathrm{ml}$ nitroblue tetrazolium in the dark for 12-24 hr at room temperature. The staining reaction was terminated by immersion in PBS with $20 \mathrm{~mm}$ EDTA, after which the sections were mounted in $50 \%$ glycerol, $5 \mathrm{~mm}$ EDTA in PBS.

For studies in which eye orientation was marked, the superior pole of each eye was lightly cauterized at the cornea following induction of deep ether anesthesia and prior to enucleation. The retinas together with the attached segment of cornea carrying the cautery mark were oriented, embedded, and sectioned. For histochemical analysis of other tissues, adult mice were anesthetized with pentobarbital, and perfused with $0.5 \%$ glutaraldehyde in PBS for $10 \mathrm{~min}$, after which the eyes, brain, kidneys, liver, testes, heart, and lungs were removed and postfixed in $2 \%$ paraformaldehyde, $0.1 \%$ glutaraldehyde in PBS for $30 \mathrm{~min}$ on ice. Each tissue was cut into pieces approximately $2 \mathrm{~mm}$ in thickness and stained with $\mathrm{X}$-gal overnight at $37^{\circ} \mathrm{C}$. The retina from a transgenic mouse, dissected free from the eyecup, served as a positive control; tissues from nontransgenic animals served as negative controls.

\section{Transgene expression profiles and topographic analysis}

Animals known to be hemizygous for the transgene were used as the standards for each line. Eyes from at least two animals from each line were marked for orientation, stained for transgene expression, and sectioned as described. Ten oriented, $10 \mu \mathrm{m}$ sections from each retina, approximately $240 \mu \mathrm{m}$ apart, were viewed by light microscopy, and the number of cone photoreceptor cells or bipolar cells expressing the transgene in each section recorded. In some cases, the retina sections were photographed to facilitate counting. For each line, the average number of stained cells of each type (cones or bipolar cells) per $10 \mu \mathrm{m}$ section was counted.

Nine eyes of adult hB-5.4lac' $Z-31$ (medium expression profile) animals were marked, enucleated, stained for $\beta$-galactosidase activity, postfixed, and sectioned as described. Pairs of adjacent sections were obtained 
A

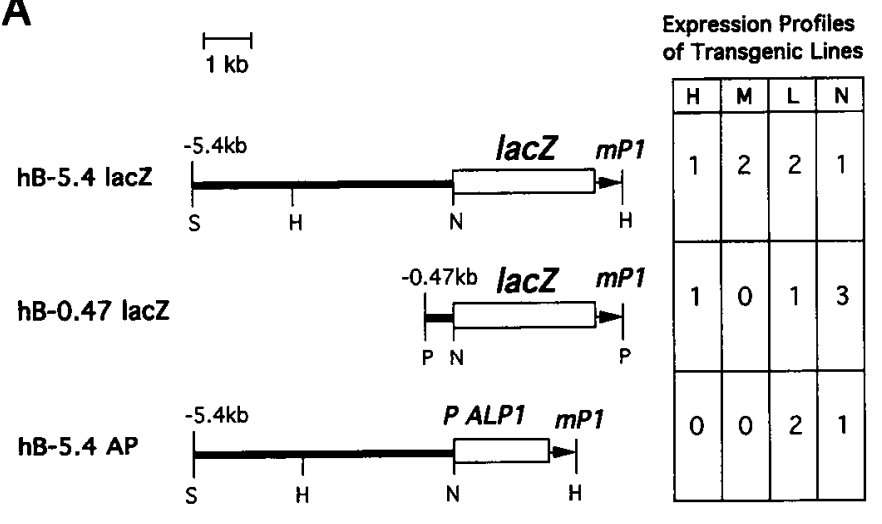

B

\begin{tabular}{l|r|r|c|}
\cline { 2 - 3 } $\begin{array}{l}\text { Average Number of Transgene-Expressing } \\
\text { Cone Photoreceptors } / 10 \mu \mathrm{m} \text { section }\end{array}$ & $30 \pm 4$ & $5.9 \pm 1.5$ & $0.2 \pm 0.1$ \\
\cline { 2 - 4 } & $640 \pm 70$ & $160 \pm 13.2$ & $2 \pm 0.6$ \\
$\begin{array}{l}\text { Average Number of Transgene-Expressing } \\
\text { Bipolar Cells / 10 } \mu \mathrm{m} \text { section }\end{array}$ & $21: 1$ & $27: 1$ & $10: 1$ \\
\hline $\begin{array}{l}\text { Ratio of Transgene-Expressing Bipolar Cells } \\
\text { to Cone photoreceptors } / 10 \mu \mathrm{m} \text { section }\end{array}$
\end{tabular}

Figure 1. Transgene constructs and expression profiles of transgenic lines. $A$, The three DNA constructs used to generate transgenic mice. Solid lines represent either the $5.4 \mathrm{~kb}$ or the $470 \mathrm{bp}$ upstream fragment from the human blue visual pigment gene. Open boxes represent DNA encoding $\beta$-galactosidase (lac $Z$ ) or human placental alkaline phosphatase (PALPI). Arrows represent the $3^{\prime}$ end of the mouse protamine 1 structural gene $(\mathrm{mPl})$, which provides an intron, a $3^{\prime}$ untranslated region, and a polyA addition site. The letters below the lines designate relevant restriction sites: $S$, SalI; $H$, HindIII; $P$, PstI; $N$, NcoI. Individual transgenic lines are referred to by a number after the designation of the transgene construct. The table to the right shows the number of transgenic lines generated from each construct that exhibit high $(H)$, medium $(M)$, low $(L)$, or no $(N)$ expression of the transgene (see below). $B$, Quantitative analysis of transgene expression profiles (see Materials and Methods). The number of transgene-expressing cells was tabulated from the retinas of at least two individuals using 10 oriented frozen retinal sections from each retina located at intervals of approximately $240 \mu \mathrm{m}$ across the retina. The table shows the mean \pm SEM. All the lines exhibiting high and medium expression profiles and two representative lines from the low expression group were analyzed.

from the center of the retina and one member of each pair immunostained with antibodies against the human blue visual pigment (JH455) and the other member with antibodies against the human red and green visual pigments (JH492). The sections were photographed to facilitate counting, and the length of each retinal section was measured and divided into eight bins of equal width. The numbers of $\beta$-gal-expressing cones or bipolar cells, and the number of photoreceptors recognized by the anti-blue or the anti-red/green antisera in each bin were recorded. For each of the eight divisions, there were 18 counts of $\beta$-galactosidaseexpressing cells and nine counts of immunostained cells for each antibody.

\section{Results}

Blue pigment transgene expression in a subset of cones and bipolar cells

To study the regulation of blue pigment gene expression, we began by asking whether sequences immediately upstream of the gene can direct expression of reporter genes to a subset of cells in the retina. Three reporter constructs were prepared and introduced into the mouse germ line: a $5.4 \mathrm{~kb}$ fragment immediately $5^{\prime}$ of the human blue visual pigment gene translation start site (Nathans et al., 1986) fused to either the gene encoding $E$. coli $\beta$-galactosidase (lacZ; hB-5.4lacZ) or a cDNA encoding human placental alkaline phosphatase ( $P A L P l ;$ hB-5.4AP), and a 470 bp fragment immediately $5^{\prime}$ of the translation start site fused to the $E$. coli $\beta$-galactosidase gene (hB-0.47lacZ; Fig. 1A).

Transgenic animals from each $\beta$-galactosidase line were tested histochemically for $\beta$-galactosidase activity in retina, brain, kidney, liver, testis, heart, and lung (see Materials and Methods). Five of six hB-5.4lacZ lines and two of five hB-0.47lac $Z$ lines express the $\beta$-galactosidase reporter exclusively in the retina; the remaining lines failed to express the reporter in any of the tissues examined (Fig. $1 A$ ). Two of three hB-5.4AP lines express the alkaline phosphatase reporter in the retina as assayed histochemically. For these three lines, the tissue distribution of transgene expression was not further investigated due to the high level of endogenous alkaline phosphatase activity in other tissues.

In each of the nine transgene-expressing lines, reporter activity in the retina was found exclusively within a subset of cones and bipolar cells. The same specificity of expression is observed with constructs carrying either the $5.4 \mathrm{~kb}$ or the $470 \mathrm{bp} 5^{\prime}$ segments, and with either the $\beta$-galactosidase or alkaline phosphatase reporters. As shown in Figures $2 A$ and $3 A-D$, transgene-expressing cells within the photoreceptor layer appear to be cones by several morphological criteria: they have wide inner segments, cell bodies close to the outer limiting membrane, and large pedicles located in the inner part of the outer plexiform layer. As described bclow, their asymmetric distribution across the retina and their colabeling with anti-blue pigment antibodies identify the transgene-expressing photoreceptors as blue cones (Figs. $4 E$, 5).

Transgene expression within the inner nuclear layer is evident in both frozen sections and whole-mounts of the retina. In Figure 2, $C$ and $D$ show an en face view of a retina from which the sclera, cornea, lens, and most of the vitreous have been removed. When viewed with a focal plane at the level of the photoreceptors (Fig. 2C), a low density of stained cones is seen, while a focal plane deep within the retina reveals a higher density of irregularly shaped cells (Fig. $2 D$ ). Based only on the $\beta$-galactosidase staining pattern, the identity of the transgene-expressing cells in the inner nuclear layer cannot easily be determined because, although the cell bodies stain strongly, the processes are poorly stained. However, cells expressing the alkaline phosphatase re-

Figure 2. $\beta$-Galactosidase transgene expression in cones and in cells in the inner nuclear layer. $A$, Ten micrometer section from the retina of an adult hB-5.4lacZ-31 animal stained with X-gal. $B$, Adult retina section from the same eye as shown in $A$ stained with hematoxylin and eosin. $O S$, outer segments; $I S$, inner segments; $O N L$, outer nuclear layer; $O P L$, outer plexiform layer; $I N L$, inner nuclear layer; $I P L$, inner plexiform layer; $G C L$, ganglion cell layer. $C$, Whole-mount retina from the same animal as in $(A)$, stained with $\mathrm{X}$-gal and viewed in the focal plane of the photoreceptor layer. $D$, The same region of retina as in $C$ viewed at a deeper focal plane to reveal transgene expression in the inner nuclear layer. Scale bars, $25 \mu \mathrm{m}$. 


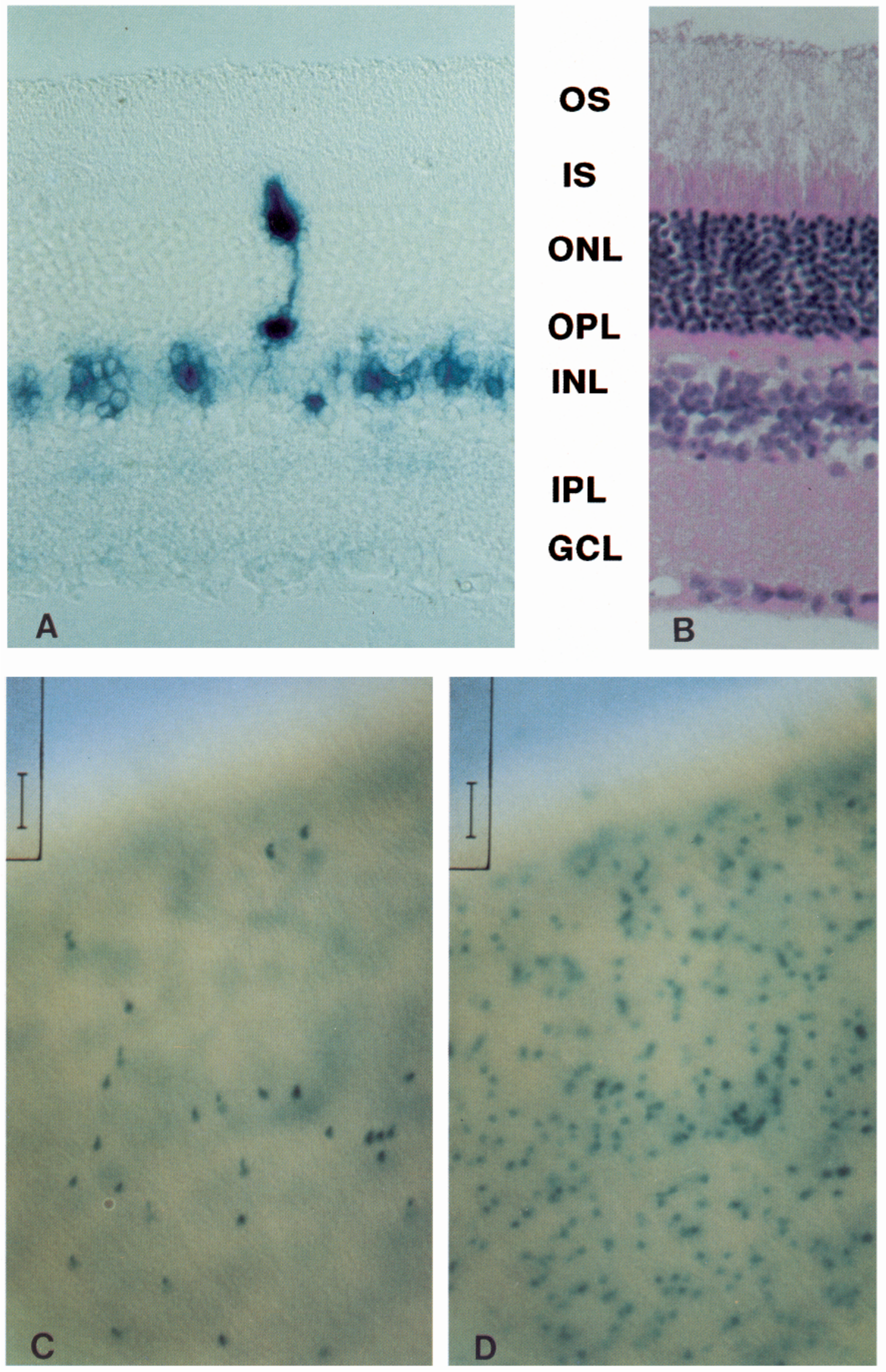



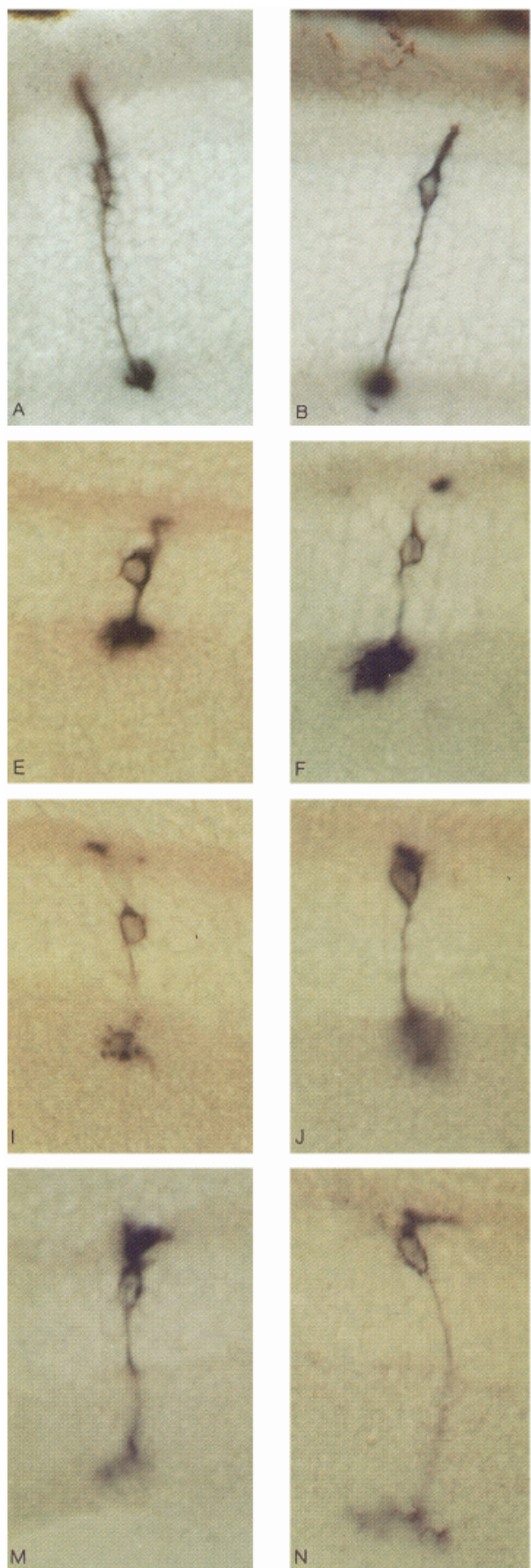

pression in cones and bipolar cells: frozen sections $(10 \mu \mathrm{m})$ of retinas from adult hB-5.4AP-6 animals stained with $\mathrm{X}$-Phos. $A-D$, Transgene expression in cone photoreceptors. $E-T$, Transgene expression in bipolar cells. $E-L, E x-$ amples of bipolar cells with axon terminals in the outer sublamina of the inner plexiform layer. $M-P$, Examples of bipolar cells with axon terminals in the inner sublamina of the inner plexiform layer. $Q-T$, Examples of clusters of transgene-expressing bipolar cells (photographed at $1000 \times$ magnification). All photomicrographs are oriented with the sclera toward the top and the vitreous toward the bottom.
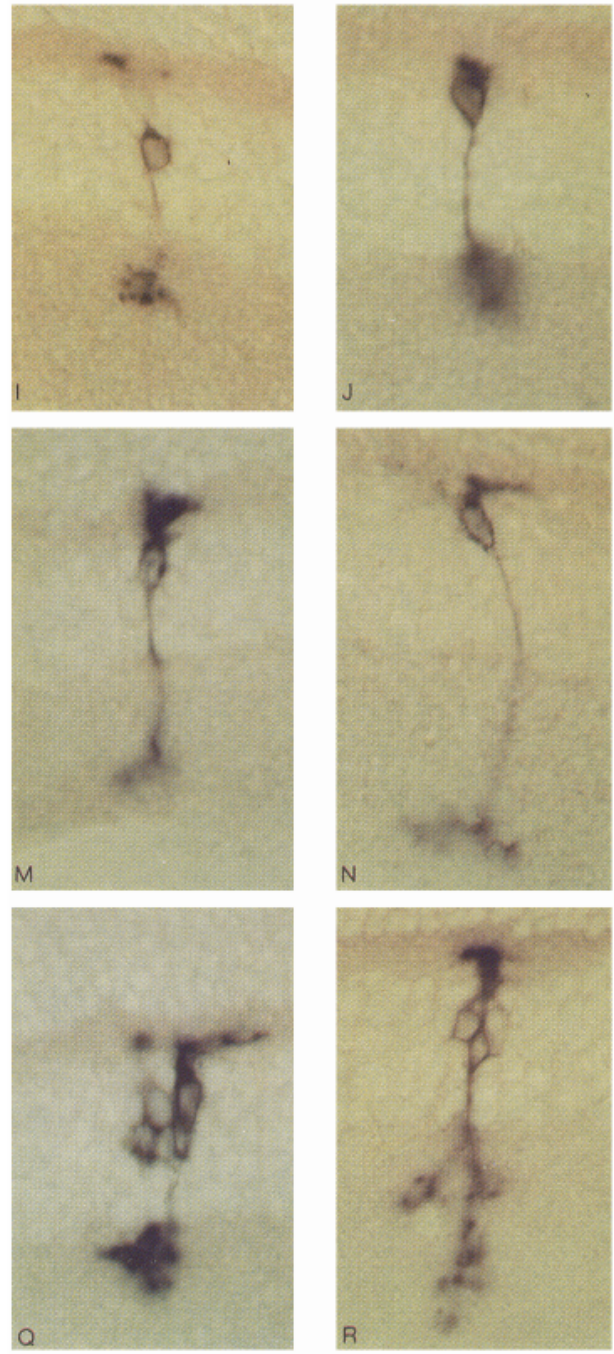
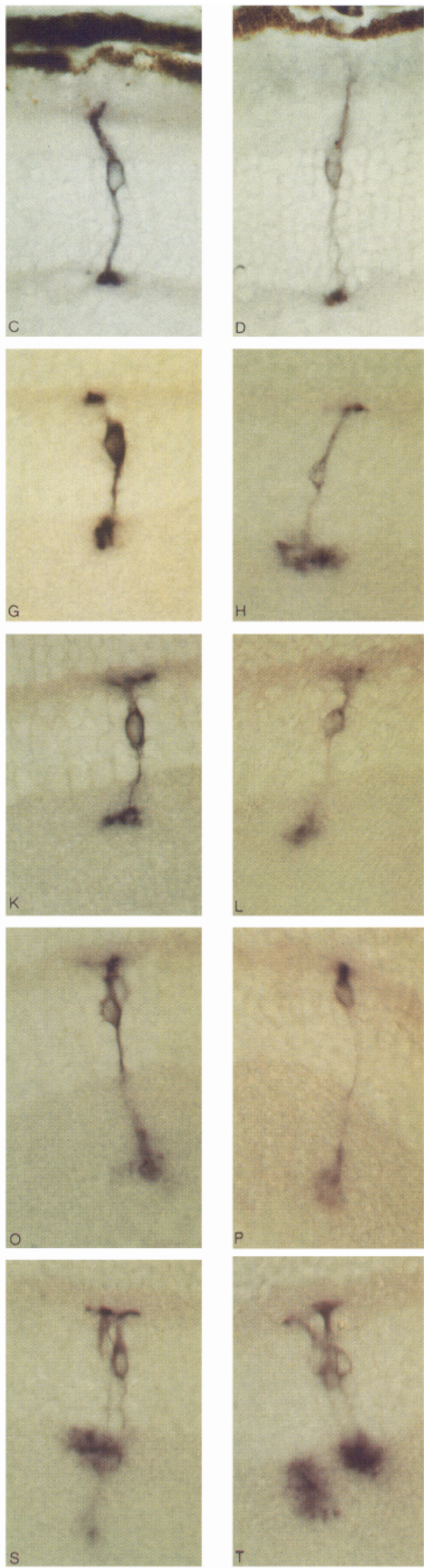
The Journal of Neuroscience, June 1994, 14(6) 3431

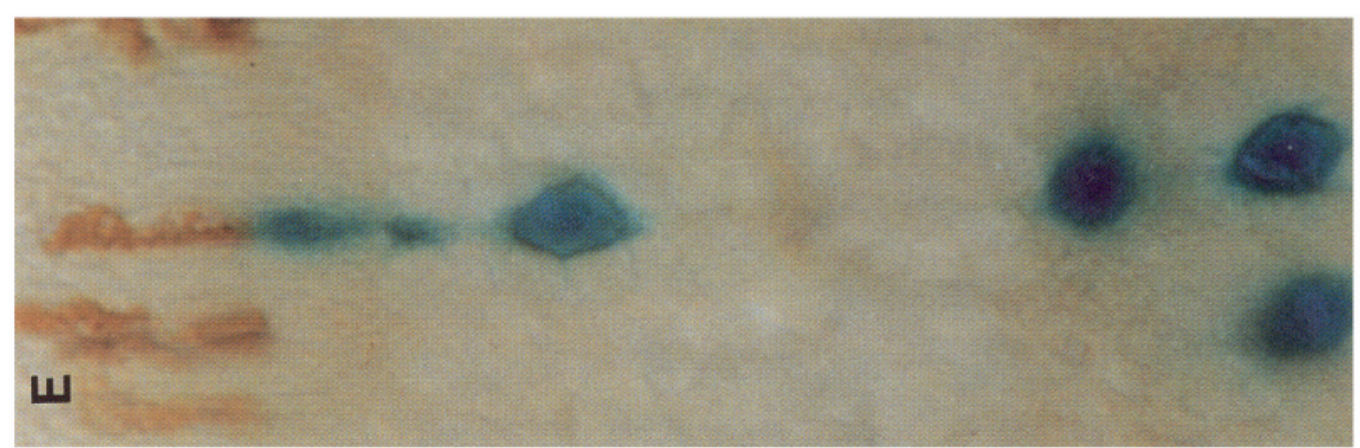

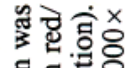

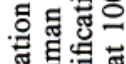

的留

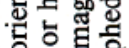

可原

둥응

굴 तै

(1)

भ?

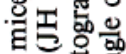

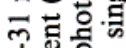

Nै

尊.

ज政

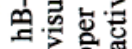

늘

응

톤 들

近定.

通它哭

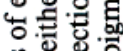

政

证

造

的察

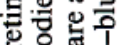

政的

到

등

苗

5.

$\rightarrow$

它宽

o

记

呟

은 잉

훙

훔. 당.

言文壁

동

势.

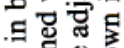

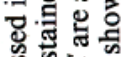

क्ष

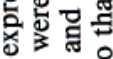

政

要

s

要

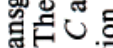

$\forall$ 청

造安

of

政응

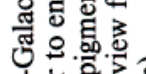

क.

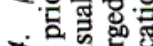

$+8 \cdot 5$

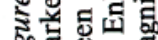

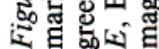


A

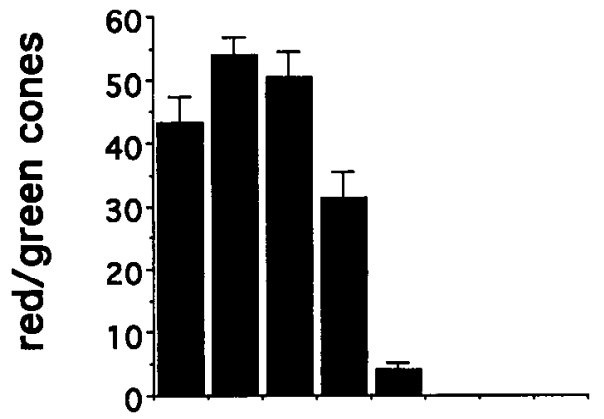

B

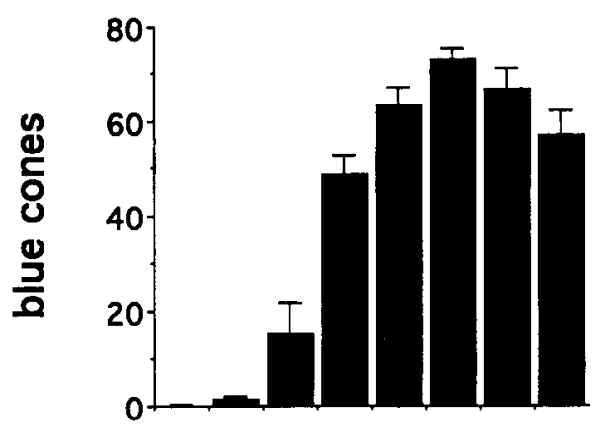

C

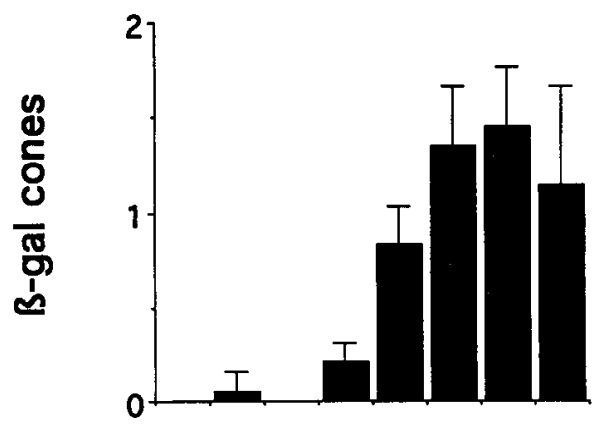

D

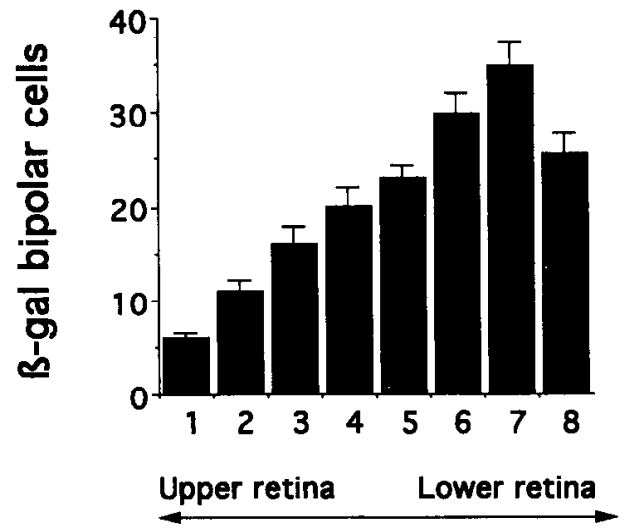

Figure 5. A gradient of transgenc cxpression in blue cones and bipolar cells: quantitative analysis of nine eyes from adult hB-5.4lacZ-31 animals processed as in Figure 4 (see also Materials and Methods). Each retina section was divided into eight regions of equal length, the numbers of X-gal-stained and antibody-stained cells were counted, and the means and SEMs from each region calculated. $A$, The number of cells recognized by antibodies against the human red/green visual pigment ( $\mathrm{JH} 492)$. $B$, The number of cells recognized by antibodies against the human blue visual pigment (JH455). $C$, The number of photoreceptors expressing $\beta$-galactosidase. $D$, The number of inner nuclear layer cells expressing $\beta$-galactosidase. porter, which is targeted to the plasma membrane, are clearly delineated and can be unambiguously identified as bipolar cells. Each of the 200 alkaline phosphatase-expressing cells in the inner nuclear layer that was examined shows a dendritic arbor in the outer plexiform layer, a cell body in the outer two-thirds of the inner nuclear layer, and a short axonal process terminating in the inner plexiform layer (Fig. $3 E-T$ ).

Three aspects of transgene expression were found to be consistent among animals within a line but to vary between lines: the total number of cones and bipolar cells that express the transgene, the ratio of transgene-expressing cones to transgeneexpressing bipolar cells, and the relative levels of transgene expression in each of the two cell types. Using animals known to be hemizygous for the transgene, each expressing line could be broadly characterized as exhibiting high, medium, or low expression profiles as determined by the total number of expressing cells (Fig. 1B). Interestingly, all lines show between 10- and 30fold more transgene-expressing bipolar cells than transgene-expressing cones. In the high-expressing lines, the transgene-expressing cones represent approximately $6 \%$ of the total cones or approximately $10 \%$ of the blue cones as determined by immunostaining with antibodies against the human red and grecn and the human blue cone pigments (see below; Wang et al., 1992). The principal differences between lines derived from the $5.4 \mathrm{~kb}$ and $470 \mathrm{bp}$ constructs appear to be in the frequency of expressing lines and in the level of transgene expression in photoreceptor cells. With the $5.4 \mathrm{~kb}$ constructs, seven of nine lines express the transgene and in these lines the staining intensity of the cone and bipolar cells is nearly equal, whereas with the 470 bp construct, two of five lines express the transgene and in both lines the staining intensity of the cone cells is lower than that of the bipolar cells.

\section{Identification of transgene-expressing cones and bipolar cells}

The mouse retina contains two classes of cones arrayed in reciprocal gradients across the retina (Szel et al., 1992; Wang et al., 1992). One class is recognized by antibodies against the carboxy-terminal 38 amino acids of the human red and green visual pigments and is most abundant in the upper retina. The other class is recognized by antibodies against the carboxy-terminal 42 amino acids of the human blue visual pigment and is most abundant in the lower retina. We presume that these cone classes express, respectively, the mouse visual pigment gene that is highly homologous to the human red and green pigment genes (Wang et al., 1992) and the mouse visual pigment gene that is highly homologous to the human blue pigment gene (see below). These cone classes most likely correspond to the long-wave and short-wave spectral sensitivities characterized electroretinographically by Jacobs et al. (1991). Although the electroretinographic experiments suggest that the short-wave mechanism is maximally sensitive near $360 \mathrm{~nm}$ and the long-wave mechanism maximally sensitive near $510 \mathrm{~nm}$, we refer, for simplicity, to the class that cross-reacts with antibodies against the human red and green visual pigments as "red/green" cones, and the class that cross-reacts with antibodies against the human blue visual pigment as "blue" cones.

To determine which class of cones express the transgenes, retinas from one hB-5.4lacZ line with a high level of $\beta$-galactosidase activity were stained sequentially with the chromogenic substrate X-gal and antibodies against either the human red/ green visual pigment or the human blue visual pigment. The results of this experiment can be summarized as follows. First, within the limits imposed by the geometry of the section, all of 
the cones that express $\beta$-galactosidase are labeled by the antiblue visual pigment antibody (Fig. $4 A, E$ ). In some instances, the inner segments (X-gal stained) and outer segments (antibody stained) are not in the same plane of section, making unambiguous assignment impossible. More often, however, the two can be seen to be continuous with each other (Fig. $4 E$ ). Second, none of the cones that express $\beta$-galactosidase are labeled with the anti-red/green visual pigment antibody (Fig. $4 C$ ). Third, the cones expressing $\beta$-galactosidase were found almost exclusively in the lower retina, where the blue cones are most abundant and red/green cones are rare (Fig. 4A,B; Wang et al., 1992).

A quantitative analysis of the spatial distribution of $\mathrm{red} / \mathrm{green}$, blue, and transgene-expressing cones is shown in Figure $5 A-C$ for hB-5.4lacZ-31, a line with an intermediate level of transgene expression. In this experiment, nine eyes were cauterized prior to enucleation to mark their orientation. The retinas were stained with X-gal and then frozen for sectioning. Two adjacent vertical sections were cut from the center of each retina, and one was stained with antibodies against the human red and green pigments and the other with antibodies against the human blue pigment. Large numbers of blue cones were observed in the lower half of each section and large numbers of red/green cones in the upper half. Each section was photographed, divided into eight bins of equal width, and the total number of cells recognized by each of the antibodies, as well as the total number of cones expressing $\beta$-galactosidase, counted for each bin. As seen in Figure $5, B$ and $C$, the two distributions of blue cones and $\beta$-galactosidase-expressing cones are nearly identical along the vertical axis.

By light microscopic examination, the vast majority of bipolar cells expressing the alkaline phosphatase reporter show the morphologic features of cone bipolar cells, as defined in a number of mammalian retinas (reviewed in Rodieck, 1988; Wassle and Boycott, 1991). Among these transgene-expressing bipolar cells, the dendritic endings do not penetrate beyond the outer edge of the outer plexiform layer where the cone pedicles reside, and they do not ramify widely in the outer plexiform layer, features that distinguish them from rod bipolar cells (Fig. $3 E-L, N-T$ ). However, occasional cells are observed in which the dendritic arbors more closely resemble those of rod bipolar cells (e.g., Fig. $3 M$ ). The transgene-expressing bipolar cells include examples of both midget and diffuse types. Most of the bipolar cells expressing the transgene have axonal arbors in the outer half of the inner plexiform layer where "off center" bipolar cells synapse (Fig. $3 E-L$ ), while approximately $25 \%$ of the cells have axonal arbors in the inner half of the inner plexiform layer where "on center" bipolar cells synapse (Fig. $3 M-P$ ). Rod bipolar cells in the mammalian retina synapse exclusively in the inner half of the inner plexiform layer. As observed for both rod and cone bipolar cells, the cell bodies of both the $\beta$-galactosidase- and alkaline phosphatase-expressing bipolar cells are underrepresented in the innermost row of cell bodies in the inner nuclear layer, where amacrine cells are found. In several instances, clusters of transgene-expressing bipolar cells were observed (Fig. $3 Q-T)$, reminiscent of the clustering of photoreceptor expression seen in some bovine rhodopsin $\beta$-galactosidase transgenic lines (Zack et al., 1991).

A quantitative analysis of the spatial distribution of $\beta$-galactosidase-expressing bipolar cells was performed as described above for cones. (A quantitative analysis was not performed on the alkaline phosphatase transgenic retinas duc to the paucity of expressing cells.) As shown in Figure 5D, the $\beta$-galactosidaseexpressing bipolar cells are arrayed in a gradient across the retina that roughly parallels the gradient of blue cones. A similar pattern was observed in each of four lines examined. As red/green cones are distributed in a gradient of opposite polarity and rods are distributed uniformly across the mouse retina, these data suggest that most of the transgene-expressing bipolar cellsidentified as cone bipolar cells on morphologic grounds-receive some or all of their synaptic input from blue cones. An alternative interpretation of the spatial gradient of transgene-expressing bipolar cells is that the transgene constructs are responding to an endogenous gradient independent of the cell type in which they are expressed, a phenomenon that was observed previously in photoreceptor cells with some mouse and bovine rhodopsin transgenes.

\section{Conserved sequences 5' of human, bovine, and murine blue visual pigment genes}

As a second approach to identifying functionally important transcriptional control sequences, we compared DNA sequences 5' of the human blue visual pigment gene with those of its bovine and murine homologs. Clones containing the murine (D. Zack, Y. Wang, and J. Nathans, unpublished observations) and bovine homologs were isolated from genomic libraries constructed in lambda EMBL3 (Frischauf et al., 1983) using a human blue pigment cDNA as a probe (Nathans ct al., 1986). $5^{\prime}$ flanking sequences of $5.4 \mathrm{~kb}, 4.6 \mathrm{~kb}$, and $2.2 \mathrm{~kb}$, were determined from the human, bovine, and murine genes, respectively. In pairwise comparisons using a dot matrix homology program (Pustell DNA matrix, McVector, New Haven, CT) the human and bovine sequences were found to share higher overall homology with each other than with the murine sequence, as reported for a similar interspecies comparison of sequences adjacent to the rhodopsin (Zack et al., 1991) and red visual pigment (Wang et al., 1992) genes. The human-murine and bovine-murine comparisons are, therefore, likely to be the most informative for identifying highly conserved sequence motifs: In each pairwise comparison, the region of highest conservation was found within the first $0.4 \mathrm{~kb} \mathrm{5}$ of the translation start site. An alignment of all three sequences within $1.0 \mathrm{~kb}$ of their respective translation start sites is shown in Figure 6. The longest continuous stretch of identical sequence (19 of 19) occurs 201-183 bp $5^{\prime}$ of the translation start of the human blue pigment gene, equivalent to 194-176 bp 5' of the transcription start site as determined by S1 mapping and cDNA extension analyses (Nathans et al., 1986). This region is contained within a stretch of $121 \mathrm{bp}$ in which $100(82 \%)$ are identical in all three species. Further $5^{\prime}$ in the sequenced regions, identities in the alignment rarely exceed four contiguous nucleotides (not shown).

\section{Discussion}

The initial goal of the experiments described here was to use transgenic mice to define those sequences within the human blue visual pigment gene that direct its expression specifically to blue cones. Unexpectedly, the blue pigment transgenes were found to be expressed in both blue cones and a subset of cone bipolar cells. The transgenes were not expressed in other cells in the retina, or, among the seven $\beta$-galactosidase-expressing lines, in any of six tissues examined, including the brain. While quantitative differences in the level and number of transgeneexpressing cells were observed between lines, all shared the same pattern of cone and bipolar cell expression. From these obscrvations, we conclude that the $5.4 \mathrm{~kb}$ and $470 \mathrm{bp}$ sequences used in the transgene constructs contain sufficient information to 
murBlue ' humBlue5. bovBlue5'

murBlue5' humBlue5' bovBlue5'

murBlue $5^{\prime}$ humBlue5 ' bovBlue5'

murBlue5 ' humBlue5' bovBlues '

murBlues ' humBlue $5^{\prime}$ bovBlues'

murBlues ' humBlue5' bovBlue5 '

murBlue ${ }^{\prime}$ humBlue $5^{\prime}$ bovBlue5'

murBlue5 ' humBlue 5" bovBlue 5 '

murBlue $5^{\prime}$ humBlue $5^{\prime}$ bovBlue $5^{\prime}$

murBlue $5^{\prime}$ humBlue5. bovBlues'

murBlue5' humBlue $5^{\prime}$ bovBlue5 '

murBlue $5^{\prime}$ humBlue ${ }^{\prime}$ bovBlue 5 '

murBlue 5 humBlue $5^{\prime}$ bovBlue 5 '

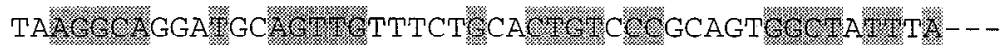

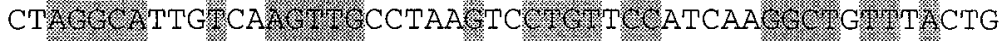

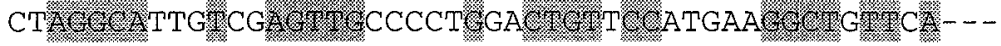

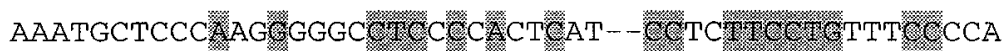

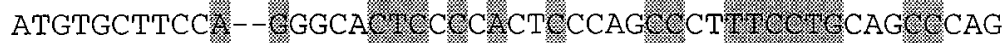

$-432$ -...---

$-460$

$-483$

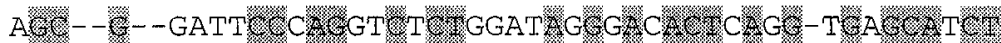
$-387$

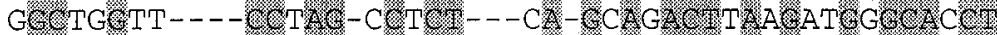

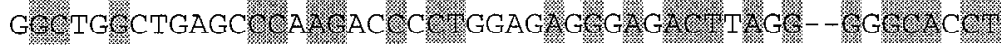

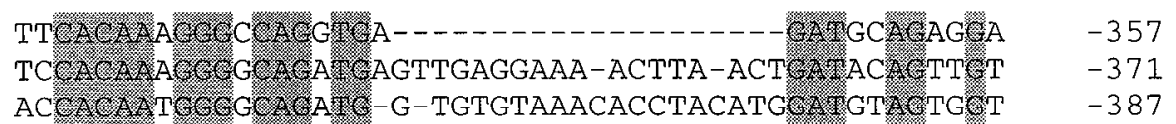

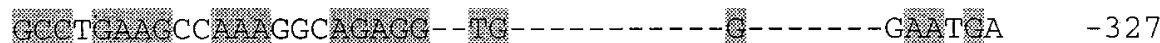

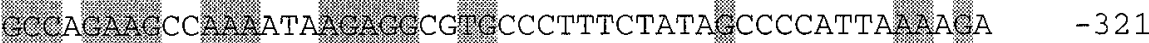

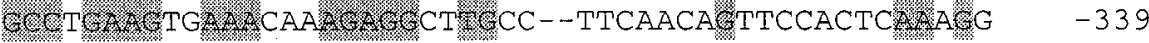

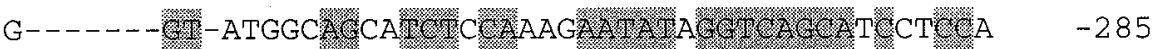

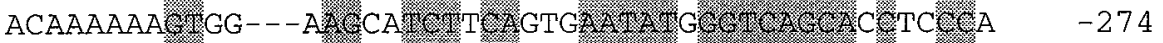

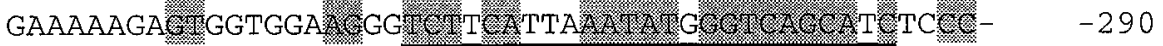

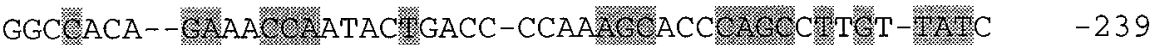

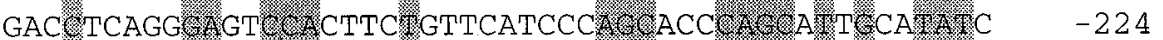

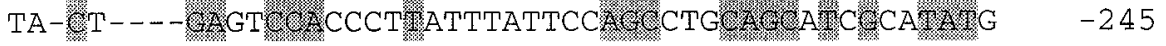

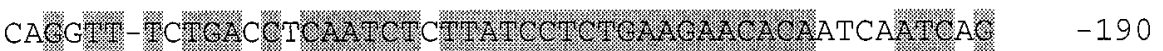

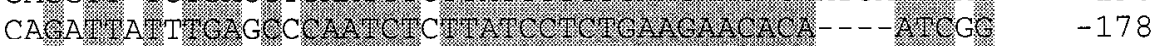

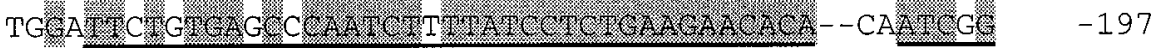

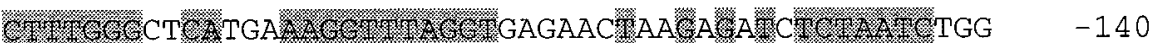

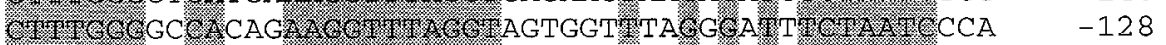

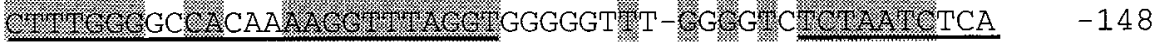

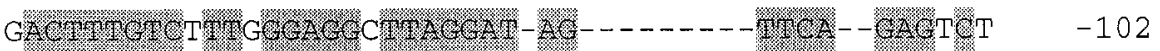

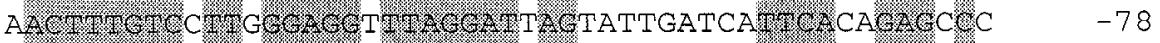

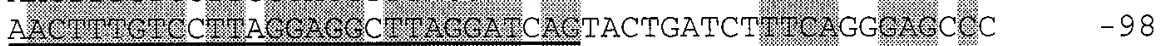

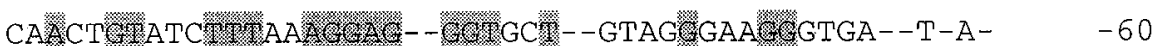

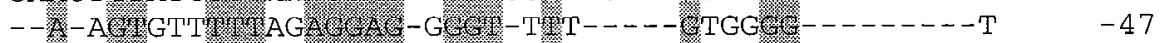

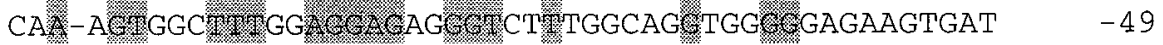

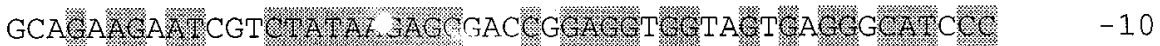

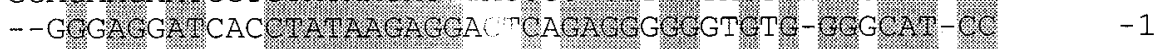

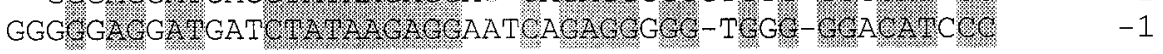

Figure 6. Alignment of sequences $5^{\prime}$ of the human, bovine, and murine blue visual pigment genes. Position -1 corresponds to the nucleotide immediately $5^{\prime}$ of the initiator methionine codon. Nucleotides conserved among the three species are shaded. Gaps in the sequence introduced to provide the best fit are represented as dashes. Sequences that are most highly conserved (window size, 25; minimum percent identity in all three sequences, $75 \%$ ) are underlined. 
direct expression of a linked reporter gene to the blue cones and to a subset of cone bipolar cells. The variable efficiency of transgene expression suggests that additional sequences normally involved in blue pigment gene expression may be missing from the constructs.

\section{Sequences that direct expression to blue cones}

The ability of a small promoter-proximal sequence to direct expression of the blue pigment transgene contrasts with the inactivity of human red pigment-derived transgenes in the absence of a locus control region located between 3.1 and $3.7 \mathrm{~kb}$ $5^{\prime}$ of the promoter (Wang et al., 1992). In the presence of the locus control region, the red pigment transgenes are expressed at high levels in all cones, a pattern not observed among any of the blue pigment transgenic lines. While the expression pattern of the red pigment transgenes indicates that there are some features of transcriptional specificity that are common to all cones, the expression pattern of the blue pigment transgenes indicates that other features are cone type specific. The small size of the transgene segments used in these experiments suggests that it will be possible to define precisely the sequences that underlie these different transcriptional specificities.

\section{Transgene expression in cone bipolar cells}

The bipolar cells that express blue pigment transgenes were identified as cone bipolar cells by morphologic criteria. This identification was possible because of the high spatial resolution obtained using the human placental alkaline phosphatase reporter. This plasma membrane enzyme has previously been expressed in cultured mammalian cells (Berger et al., 1987), and used as a histochemical marker in cell-lineage studies in the retina (Fields-Berry et al., 1992). The experiments reported here suggest that it should be generally useful for transgenic studies in which expressing cells are analyzed morphologically.

We consider below both the possible mechanisms and the functional significance of expression of human blue pigment transgenes in cone bipolar cells. Staining of the mouse retina with antibodies raised against the carboxy-terminal 42 amino acids of the human blue pigment has provided no evidence for accumulation of the mouse blue pigment in any cells other than a subset of cone photoreceptors. This discrepancy between the presumptive pattern of expression of the endogenous blue pigment gene and of the human blue pigment transgenes could result either from an absence of rcgulatory scquences in the transgene fragments or from a difference between the human and mouse DNA sequences. In the former case, we would predict that the missing element represses blue pigment gene expression in cone bipolar cells. In the latter case, a negative regulatory element contained within the transgene fragment may have diverged sufficiently between humans and mice that it is no longer efficiently recognized in muuse cone bipolar cells. In both cases an underlying similarity in positive regulatory sequences is inferred for cones and cone bipolar cells. Alternatively, we might suppose that cone and cone bipolar cells do not have any particular similarity in transcriptional specificity, and that the human blue pigment gene has, by chance, evolved to contain sequences that resemble those used in mouse cone bipolar cells. In this case, it would be a remarkable coincidence that, of all the sequence changes possible in the human blue pigment gene, the ones observed should confer activation in those cells with which the cones synapse.
What might be the biological significance of a partial overlap in transcriptional specificity between cones and cone bipolar cells? One possibility is that the blue pigment is produced in some or all cone bipolar cells at a level below the present limit of detection. Under this scenario, the blue pigment might be used independently as a light sensor in bipolar cells, or have some other role, perhaps as a surface recognition molecule. A second possibility is that some other genes share transcriptional controlling sequences with the blue pigment gene and are expressed in both blue cones and cone bipolar cells. The requirement for mutual expression of a set of genes would constrain the evolutionary divergence of cone and bipolar cell transcriptional specificities. A third possibility, and one that does not exclude the first two, is that the shared specificity reflects a hierarchical path of retinal cell commitment, in which pairs of related or interacting cells share a number of transcriptional regulators. This general idea is compatible with the observation that different cell types in the retina are often siblings from the final mitosis of a common parent (Turner and Cepko, 1987; Turner et al., 1990).

\section{References}

Berger J, Howard AD, Gerber L, Cullen BR, Udenfriend S (1987) Expression of active, membrane-bound human placental alkaline phosphatase by transfected simian cells. Proc Natl Acad Sci USA 84: $4885-4889$.

Dowling JE (1987) The retina. An approachable part of the brain. Cambridge, MA: Belknap.

Fields-Berry SC, Halliday AL, Cepko CL (1992) A recombinant retrovirus encoding alkaline phosphatase confirms clonal boundary assignment in lineage analysis of murine retina. Proc Natl Acad Sci USA 89:693-697.

Frischauf A-M, Lehrach H, Poustka A, Murray N (1983) Lambda replacement vectors carrying polylinker sequences. J Mol Biol 170: $827-842$.

Hogan B, Constantini F, Lacy E (1986) Manipulating the mouse genome. Cold Spring Ilarbor, NY: Cold Spring Harbor Laboratory.

Holt CE, Bertsch TW, Ellis HM, Harris WA (1988) Cellular determination in the Xenopus retina is independent of lineage and birth date. Neuron 1:15-26.

Ibbotson RE, Hunt DM, Bowmaker JK, Mollon JD (1992) Sequence divergence and copy number of the middle and long-wave photopigment genes in Old World monkeys. Proc R Soc Lond [Biol] 247:145154.

Jacobs GH, Neitz J, Deegan JF (1991) Retinal receptors in rodents maximally sensitive to ultraviolet light. Nature 353:655-656.

Johnson RL, Grant KB, Zankel TC, Boehm MF, Merbs SL, Nathans J, Nakanishi K (1993) Cloning and expression of goldfish opsin sequences. Biochemistry 32:208-214.

Kouyama N, Marshak DW (1992) Bipolar cells specific for blue cones in the macaque retina. J Neurosci 12:1233-1252.

Kuwata O, Imamoto Y, Okano T, Kokame K, Kojima D, Matsumoto H, Morodome A, Fukada Y, Shichida Y, Yasuda K, Shimura Y, Yoshizawa T (1990) The primary structure of iodopsin, a chicken red-sensitive cone pigment. FEBS Lett 272:128-132.

Lem J, Applebury ML, Falk JD, Flannery JG, Simon MI (1991) Tissue-specific and developmental regulation of rod opsin chimeric genes in transgenic mice. Neuron 6:201-210.

Mariani AP (1984) Bipolar cells in monkey retina selective for the cones likely to be blue-sensitive. Nature 308:184-186.

Nathans J, Thomas D, Hogness D (1986) Molecular genetics of human color vision: the genes encoding blue, green, and red pigments. Science 232:193-202.

Neitz M, Neitz J, Jacobs GH (1991) Spectral tuning of pigments underlying red-green color vision. Science 252:971-974.

Oberdick J, Smeyne RJ, Mann JR, Zackson S, Morgan JI (1990) A promoter that drives transgene expression in cerebellar Purkinje and retinal bipolar neurons. Science 248:223-226.

Peschon JJ, Behringer RR, Brinster RL, Palmiter RD (1987) Sper- 
matid-specific expression of protamine 1 in transgenic mice. Proc Natl Acad Sci USA 84:5316-5319.

Rodieck RW (1973) The vertebrate retina. Principles of structure and function. San Francisco: Freeman.

Rodieck RW (1988) The primate retina. Comp Primate Biol 4:203278.

Szèl A, Rohlich P, Caffe AR, Juliusson B, Aguirre G, Veen TV (1992) Unique topographic separation of two spectral classes of cones in the mouse retina. J Comp Neurol 325:327-342.

Takao M, Yasui A, Tokunaga F (1988) Isolation and sequence determination of the chicken rhodopsin gene. Vision Res 28:471-480.

Tokunaga F, Iwasa T, Miyagishi M, Kayada S (1990) Cloning of cDNA and amino acid sequence of one of chicken cone visual pigments. Biochem Biophys Res Commun 173:1212-1217.

Turner DL, Cepko CL (1987) A common progenitor for neurons and glia persists in rat retina late in development. Nature 328:131-136.
Turner DL, Snyder EY, Cepko CL (1990) Lineage-independent determination of cell type in the cmbryonic mouse retina. Neuron 4:833845

Wang Y, Macke JP, Merbs SL, Zack DJ, Klaunberg B, Bennett J, Gearhart J, Nathans J (1992) A locus control region adjacent to the human red and green visual pigment genes. Neuron 9:429-440.

Wassle H, Boycott BB (1991) Functional architecture of the mammalian retina. Physiol Rev 71:447-480.

Yokoyama R, Yokoyama S (1990) Convergent evolution of the redand green-like visual pigment genes in fish Astyanax fasciatus, and human. Proc Natl Acad Sci USA 87:9315-9318.

Zack DJ, Bennett J, Wang Y, Davenport C, Klaunberg B, Gearhart J, Nathans J (1991) Unusual topography of bovine rhodopsin promoter-lacZ fusion gene expression in transgenic mouse retinas. Neuron 6:187-199. 